\title{
Fuzzy Multi-Criterial Choice of Geological and Technical Measures
}

\author{
Oleg Yuryevich Panischev', Yuri Vladimirovich Davydov², Igor Vyacheslavovich Anikin ${ }^{3}$, Dina Vladimirovna Kataseva ${ }^{4}$, \\ Alexey Sergeevich Katasev ${ }^{5}$, Amir Muratovich Akhmetvaleev \\ ${ }^{1}$ Researcher, Research Laboratory for Near Space Research, Kazan (Volga Region) Federal University, Russia. \\ Scopus ID: 8355604900; ORCID: 0000-0001-5490-912X, \\ ${ }^{2}$ Research laboratory assistant, Research Laboratory "Microwave Design and Radio Telecommunications", \\ Kazan (Volga Region) Federal University, Russia. ORCID: 0000-0002-4849-720X, \\ ${ }^{3}$ Doctor of Engineering, Professor, Head of the Department of Information Security Systems at the Institute of Computer \\ Technologies and Information Protection, Kazan National Research Technical University named after A.N. Tupolev-KAI; \\ Kazan National Research Technical University named after A.N. Tupolev, Russia. \\ Scopus ID: 56538191100; ORCID: 0000-0001-9478-4894, \\ ${ }^{4}$ Senior Lecturer, Department of Information Security Systems, Institute of Computer Technologies and Information Protection, \\ Kazan National Research Technical University named after A.N. Tupolev-KAI; Kazan National Research Technical University \\ named after A.N. Tupolev, Russia. Scopus ID: 57193401954; ORCID: 0000-0001-6141-8329, \\ ${ }^{5}$ Doctor of Engineering, Professor of the Department of Information Security Systems at the Institute of Computer Technologies \\ and Information Protection, Kazan National Research Technical University named after A.N. Tupolev-KAI, Kazan National \\ Research Technical University named after A.N. Tupolev, Russia. Scopus ID: 57193408902; ORCID: 0000-0002-9446-0491,
}

\begin{abstract}
${ }^{6} \mathrm{PhD}$ in Engineering, Associate Professor of the Department of Information Security Systems at the Institute of Computer Technologies and Information Security, Kazan National Research Technical University named after A.N. Tupolev-KAI; Kazan National Research Technical University named after A.N. Tupolev, Russia. Scopus ID: 57202913457;
\end{abstract}

ORCID: 0000-0003-0384-9539,

\begin{abstract}
The work solves the problem of automating the process planning of assigning geological and technical measures (GTM) at oil fields in conditions of uncertainty. A decision support system is being developed to help an expert make an informed decision about the method of influence of geological and technical measures on an oil reservoir. From the point of view of the imposed restrictions on the choice of geological and technical measures, various types of geological and physical parameters are highlighted. To solve this problem, a fuzzy-production model is proposed for the representation of expert knowledge. A feature of this model is the possibility of different types of parameters use to impose restrictions on the choice of geological and technical measures, using fuzzy restrictions and setting their weights, as well as formalizing the degree of an expert confidence in the reliability of the rule being formed. They provided the possibility of fuzzy modifier use in the conditions of fuzzy production rules for fuzzy constraint correction. To determine the weights of fuzzy constraints in the conditions of the rules, an approach is used based on a multi-criteria assessment of constraints, carried out using the hierarchy analysis method (HAM). The following were used as the criteria for evaluation the weights: the importance of the corresponding geological and physical parameter for an expert, the completeness of the available information on the studied parameter, the relevance of the values, the complexity of obtaining the values. The final choice of geological and technical measures is carried out on the basis of a fuzzy multi-criteria choice according to the following
\end{abstract}

criteria: satisfaction of the fuzzy production model limitations, high technological efficiency, high economic effect, and the impact on the environment. Based on the knowledge of experts, a knowledge base has been formed that includes fuzzy production rules for choosing 81 different geological and technical measures at production wells using the restrictions on 15 geological and physical parameters. The knowledge base has been tested at the wells of the Feofanovskoye field, Alkeevskaya, Chishminskaya areas. The development of recommendations was carried out in conditions of information incompleteness on a number of parameters of the set. The results generated by the decision support system correspond to the decisions made by the experts.

Keywords- Knowledge Base, Fuzzy Logic, Fuzzy Production Model, Geological And Technical Event, Hierarchy Analysis Method, Decision Support

\section{INTRODUCTION}

At present, the problem of oil field development efficiency increase [1-3], especially those at the late stage of their development [4], is becoming increasingly important. This stage is characterized by the presence of a large share of hard-to-recover oil reserves, and its extraction rate decrease $[5,6]$. To stabilize the rate of oil withdrawal at the late stage, geological and technical measures (GTM) are often carried out $[7,8]$, the choice of which is carried out by the experts of oil and gas production departments (OGPD). 
When they plan the sequence of geological and technical measures in an oil field, the experts face many difficulties, the main of which are the following ones [9]:

1) multicriteria of the problem being solved, subjectivity and unequal criteria for geological and technical measure selection;

2) the uncertainty of the available information, expressed in the vagueness of the imposed restrictions on the choice of geological and technical measures, possible inaccuracy and incompleteness of the geological and technical information stored in the database of the OGPD [10, 11].

These difficulties make it difficult to solve efficiently the task of planning geological and technical measures by the experts of OGPD, which leads to the need to develop a knowledge representation model for them [12] and a decision support system [13-16], which helps to select geological and technical measures in the conditions of the above difficulties. These issues were studied in the works by R.Kh. Muslimov, N.A. Eremin, A.E. Altunin and others [1719]. However, they did not cover all of the above complexities. This article is devoted to this issue solution.

\section{METHODS}

The main information for the selection of effective geological and technical measures in oil fields (which allow to ensure the target levels of oil production) are the operating conditions of a development object, determined by geological and physical parameters [20]. The problem of GTM choice to be solved is determined as follows.

Let us denote a set of geological and technical measures through $\mathrm{T}, \Pi=\left\{P_{i}\right\}_{i=1, p}-$ operating conditions of the development object - geological and physical parameters (GPP), $C=\left\{C_{i}\right\}_{i=1, \gamma}$ - the criteria for selection geological and technical measures. It is required to find one or several geological and technical measures, the purpose of which is the most expedient in the current conditions.

From the point of view of the imposed restrictions on the choice of GTM, geological and 1) a list of values;

2) numerical without gradations with restrictions in the form of a numerical segment characterizing the lower and upper boundaries;

3) a list of gradations with restrictions in the form of linguistic categories (the set of numerical intervals).

To represent the expert's knowledge about the choice of geological and technical measures based on the values of geological and physical parameters, it is proposed to use the modernized form of fuzzy products "IF $<$ list of conditions $>$ THEN <decision taken $>$ " [22]. To take into account the difficulties listed earlier in making decisions, a modified model of the following form was proposed [23]:

$$
R_{j}:\left(P^{j}, \tilde{A}^{j}, w^{j}, C F^{j}, T^{j}\right)
$$

In this model $P^{j}=\left\{P_{i}^{j}\right\}, P_{i}^{j} \in \Pi-$ a set of parameters, $\tilde{A}^{j}$ - a set of restrictions on the parameters specified in a fuzzy form, $w^{j}-$ the weights of restrictions $\tilde{A}^{j}$, $C F^{j} \in[0 ; 1]$ - the reliability degree of the rule $R_{j}$, $T^{j} \in T-$ GTM, recommended to be carried out in an oil field while meeting the specified restrictions.

Clear constraints on the parameters of the set $P^{j}$ are defined as an enumeration of a list of possible values or numerical ranges. The fuzzy constraints $\tilde{A}_{i}^{j}$ for the parameters of the 2 nd and the 3rd types are formed by blurring the left and right boundaries of the numerical intervals established by expert [24, 25]. The blurring of numerical intervals is carried out using fixed blur modifiers [26, 27], converting these intervals into fuzzy L-R-type intervals [28], taking into account a fixed percentage of the numerical value of clear interval boundaries. In this paper, it is proposed to use the following blur modifiers: CLOSE (5\% of blur), ABOUT (10\%), APPROXIMATE (25\%), COARSE (50\%). Fuzzy restrictions on the parameters of the "List of values" type are determined using the membership function, formed by an expert way [29-31]. The weights of fuzzy constraints $w^{j}$ are formed expertly using the hierarchy analysis method [32]. The method of forming the weights will be discussed below.

For the operation of the decision support system, using the knowledge of experts in the form of the model (1), it is required to determine the operation scheme of the inference machine (IM). This IM should operate on the proposed rules, as well as form decisions in the event of a possible lack of information on a number of parameters.

The following scheme of IM work is proposed, which forms the final result based on a set of intermediate assessments.

1. Calculation of operation degree concerning the following conditions $S_{R_{j}} \in[0 ; 1]$ of the specific rule $R_{j}$. This assessment determines the complex degree of satisfaction of the actual GFP values $P_{i}^{j} \in P^{j}$ to the restrictions $\tilde{A}_{i}^{j} \in \tilde{A}^{j}$ imposed on them in the rule. It is formed on the basis of calculation the degrees of membership of the parameter real values to the constraint membership functions taking into account the weights $w^{j}$.

2. The calculation of confidence degree to the formed decision $S_{D_{j}} \in[0 ; 1]$. This estimate expresses the completeness of the initial information about the GFP values $P_{i}^{j} \in P^{j}$. Its value is determined as the ratio of the restriction total weight of the known parameter values to the total weight of all restrictions in the rule under consideration. 
3. Assessment of reliability degree concerning the rule $C F^{j} \in[0 ; 1]$. This assessment characterizes the expert's confidence in the universality of the rule $R_{j}$ and is assigned to the rule by the expert himself.

4. The assessment of the final coefficient of reliability $\operatorname{Comp}_{R_{j}}$. This estimate determines the final degree of decision reliability taken by the rule $R_{j}$ and is formed on the basis of previously calculated estimates as follows: $\operatorname{Comp}_{R_{j}}=S_{R_{j}} \cdot S_{D_{j}} \cdot C F^{j}$.

5. The assessment of the recommendation reliability $T E_{k}$ on GTM technology use is determined in the case of a conflict set in the inference engine. To resolve the conflict, the maximum final confidence factor is determined $T E_{k}=\max _{j=1, \ldots, t_{k}} \operatorname{Comp}_{R_{j}}, R_{j} \in \bar{R}_{k}$.

To form the weights of fuzzy constraints in the conditions of the rules, an approach is used based on a multi-criteria assessment of constraints carried out with the help of the MAI [32]. The following were used as the criteria for evaluating the weights:

- $K_{l}=$ the importance of the geological and physical parameter for an expert (this criterion determines the priority of the studied parameter use by an expert when they decide on the assignment of GTM);

$-K_{2}=$ completeness of available information on the parameter under study $P_{i} \in \prod$ (incompleteness of information on the parameter reduces its preference for use in the decision support system);

- $K_{3}=$ the relevance of the parameter $P_{i} \in \Pi$ values (the fact that the database used stores, for example, aggregated or averaged values of the parameter $P_{i}$, can reduce the weight of this parameter in the decision support system);

- $K_{4}=$ the complexity of setting the parameter $P_{i} \in \Pi$ values.

In addition, it is proposed to carry out a fuzzy multi-criteria choice of GTM technologies in the presence of the following parameters:

- $\widetilde{C}_{1}=\ll$ Satisfaction with the constraints of the fuzzy production model» - characterizes the satisfaction of the GFP $P_{i}^{j}$ with the fuzzy constraints $\tilde{A}_{i}^{j}$ imposed on them;

- $\widetilde{C}_{2}=$ "High technological efficiency» in the form of volumes of additionally produced oil;

- $\widetilde{C}_{3}=$ «High economic effect $»-$ characterizes the expected effect in monetary terms at GTM value;
- $\widetilde{C}_{4}=$ «Impact on the environment» - characterizes the lack of technology impact $T^{j} \in T$ on the ecology of the environment.

Let's denote the fuzzy set of preference of alternatives via $\widetilde{C}=\left\{\mu_{C}\left(T^{l}\right) / T^{l}, \ldots, \mu_{C}\left(T^{n}\right) / T^{n}\right\}$ by the criterion $\widetilde{C}$. Then, in the presence of $\alpha_{r}$ criteria, the final choice of alternatives is carried out according to the formula $\tilde{D}=\tilde{C}_{1}^{\alpha_{1}} \bigcap \widetilde{C}_{2}^{\alpha_{2}} \bigcap \ldots \tilde{C}_{r}^{\alpha_{r}}$. It is proposed to determine the weights of the criteria $\alpha_{i}$ using the hierarchy analysis method [32]. The alternative with the highest value of the set $\tilde{D}$ membership function is chosen as the best.

\section{RESULTS AND DISCUSSION}

With the help of the MAI, the weights of the $\mathrm{K}_{1}-\mathrm{K}_{4}$ criteria were formed, used in calculating the importance of the restrictions $\tilde{A}_{i}^{j} \in \tilde{A}^{j}$, presented in Table 1 .

Table 1. Weights of Criteria K1-K4

\begin{tabular}{|c|c|}
\hline Criterion & Weight \\
\hline$K_{1}$ & 0,652 \\
\hline$K_{2}$ & 0,204 \\
\hline$K_{3}$ & 0,102 \\
\hline$K_{4}$ & 0,042 \\
\hline
\end{tabular}

The weights of the constraints on the parameters $P_{i} \in \prod$ by the criterion $K_{1}$ are set by the expert method independently for each rule $R_{j}$ according to the Table 2 .

Table 2. Parameter $P_{i} \in \prod_{\text {Weights By Criterion K1 }}$

\begin{tabular}{|c|c|}
\hline Weight & $\begin{array}{c}\text { Linguistic interpretation of } \\
\text { importance }\end{array}$ \\
\hline 0,2 & very weak \\
\hline 0,4 & not strong \\
\hline 0,6 & moderate \\
\hline 0,8 & important \\
\hline 1 & very important \\
\hline
\end{tabular}

The set of parameters used by the decision support system and their weights according to $\mathrm{K}_{2}-\mathrm{K}_{4}$ criteria, calculated using the MAI, are presented in Table 3. Further, the final weight of the parameter in the rule was determined as the product of all weights. 
Table 3. The Set of Parameters 11 and Their Importance Weights by Criteria K2-K4

\begin{tabular}{|l|c|c|c|}
\hline \multirow{2}{*}{\multicolumn{1}{|c|}{ Parameter }} & \multicolumn{3}{c|}{ Weight by criterion } \\
\cline { 2 - 4 } & $K_{2}$ & $K_{3}$ & $K_{4}$ \\
\hline Horizon type & 0,07 & 0,1 & 0,14 \\
\hline Collector type & 0,07 & 0,1 & 0,14 \\
\hline Reservoir pressure & 0,02 & 0,01 & 0,06 \\
\hline Bottomhole pressure & 0,01 & 0,04 & 0,04 \\
\hline Water production & 0,14 & 0,07 & 0,04 \\
\hline Production water cut & 0,14 & 0,07 & 0,04 \\
\hline Oil flow rate & 0,14 & 0,07 & 0,04 \\
\hline Well type & 0,19 & 0,18 & 0,16 \\
\hline Heterogeneity & 0,02 & 0,03 & 0,06 \\
\hline Falling productivity rate & 0,01 & 0,04 & 0,04 \\
\hline Reservoir injectivity & 0,03 & 0,03 & 0,03 \\
\hline $\begin{array}{l}\text { The presence of removal of } \\
\text { mechanical impurities }\end{array}$ & 0,01 & 0,10 & 0,01 \\
\hline $\begin{array}{l}\text { Decrease in production rate } \\
\text { after well workover (ORS) }\end{array}$ & 0,01 & 0,04 & 0,04 \\
\hline $\begin{array}{l}\text { Well workover, not related } \\
\text { to waterproofing }\end{array}$ & 0,02 & 0,11 & 0,11 \\
\hline $\begin{array}{l}\text { Density of residual balance } \\
\text { reserves }\end{array}$ & 0,11 & 0,02 & 0,04 \\
\hline
\end{tabular}

Using the hierarchy analysis method, the following criteria $\widetilde{C}_{1}-\widetilde{C}_{4}$ weights were determined: $\alpha_{1}=2,136 ; \alpha_{2}=0,292$; $\alpha_{3}=0,788 ; \alpha_{4}=0,788$. Based on these weights, a final fuzzy set $\tilde{D}$ of GTM recommended for appointment was formed:

$$
\tilde{D}=\widetilde{C}_{1}^{2.136} \bigcap \widetilde{C}_{2}^{0.292} \bigcap \widetilde{C}_{3}^{0.788} \bigcap \tilde{N}_{4}^{0.788}
$$

The proposed approach to multi-criteria decision making is implemented in the decision support system, which forms recommendations on the appointment of GTM in production wells, guided by generalized expert experience formalized in the form of the model (1).

\section{SUMMARY}

Based on the knowledge of experts, a knowledge base was formed [33], including fuzzy production rules for selection 81 different geological and technical measures at production wells using the restrictions on 15 geological and physical parameters. The knowledge base has been tested at the wells of the Feofanovskoye field, Alkeevskaya, and Chishminskaya areas. The development of recommendations was carried out in conditions of data incompleteness on a number of parameters of the set. The results generated by the decision support system correspond to the decisions made by the experts.

\section{CONCLUSIONS}

One of the main problems when appointing geological and technical measures at oil fields as an expert is the multicriterion nature of the problem being solved, the subjectivity and unequality of the criteria for selecting geological and technical measures, the uncertainty of the available information, expressed in the vagueness of imposed restrictions on the choice of geological and technical measures, possible inaccuracy and incompleteness of geological and technical information stored in the OGPD database. These difficulties make it difficult to solve effectively the task of planning geological and technical measures by OGPD experts. To solve this problem, the paper proposes an approach to the development of a decision support system based on a new model of expert knowledge representation and a corresponding fuzzy inference scheme. The final choice of geological and technical measures is carried out on the basis of a fuzzy multi-criteria choice. The use of MAI made it possible to take into account the inequality of the criteria for selecting geological and technical measures. The final analysis of the results concerning GTM assignment, formed by the decision support system, showed that the results obtained correspond to the decisions made by the experts.

\section{ACKNOWLEDGEMENTS}

The work is performed according to the Russian Government Program of Competitive Growth of Kazan Federal University. This work was financially supported by the Ministry of Science and Higher Education of the Russian Federation in the framework of the Federal Target Program «Research and Development in Priority Directions for the Development of the Scientific and Technological Complex of Russia for 2014- 2020» under the agreement on granting subsidies No. 05.604.21.0253 dated 12/02/19 on the topic «Creating technology for longterm investment planning for the effective development of oil fields based on high-performance computing and machine learning», a unique identifier is RFMEFI60419X0253.

\section{REFERENCES}

[1] Nasybullin AV, Sattarov R, Latifullin FM, Denisov OV, Chirikin AV. Creation of software tool for long-term investment planning with a view to the effective development of oil fields (Russian). Oil Industry Journal. 2019 Dec 1;2019(12):128-31.

[2] Buana YS, Adisatria MA, Azizurrofi AA. Paper production cost analysis of improved oil recovery projects based on field development plan in Indonesia. Society of Petroleum Engineers - SPE Kuwait Oil and Gas Show and Conference, KOGS. 2019. 
[3] Kireeva TA. Cationic exchange between injected water and rock as a scaling factor in oil fields development (Russian). Oil Industry Journal. 2019 Sep 1;2019(09):86-9.

[4] Galimov IF, Gubaidullin FA, Vakhin AV, Isaev PV. Analyzing effectiveness of the terrigenous reservoirs hydrofracturing at South-Romashkinskaya area of Romashkinskoe oil field at the late stage of development (Russian). Oil Industry Journal. 2018 Jan 1;2018(01):52-4.

[5] Serdyuk A, Valeev S, Frolenkov A, Lushnikov A, Overin A, Yudin A, Kuznetsov A, Gorlushko A. Improving Economics of Hard-to-Recover Reserves Development. Case Study of Achimov Formation at Prirazlomnoe Oil Field. InSPE Russian Petroleum Technology Conference 2018 Oct 15 . Society of Petroleum Engineers.

[6] Khisamov ${ }^{1}$ RS, Miyassarov AS, Khuzin RR, Salikhov DA, Andreev VE. Improvement Of The Development Efficiency Of Reserves Difficult To Recover Using Horizontal And Multibranch Wells On The Example Of Nekrasovsky Field Develфoped By Carbon-Oil Llc. Georesursy. 2017 Jan 1;19(3):204-8.

[7] Tomashev DV, Nelepov MV, Papotnaya AA. The Influence of Planetary Geodynamics on the Success of Geological and Technical Measures for the Development of Oil and Gas Fields. InGeoBaikal 20182018 Aug 11 (Vol. 2018, No. 1, pp. 1-4). European Association of Geoscientists \& Engineers.

[8] Ramazanov RR, Kharlamov KA, Letko II, Martsenyuk RA. Efficiency analysis of geological and technical measures (Russian). Oil Industry Journal. 2019 Jun 1;2019(06):62-5.

[9] Bukhanov DA, Kramar OV. PDGGM is as a tool of raising the quality of planning the geological and technical measures (the application experience on the object UV1 Nong-Yeganskoe oil-field). In16th Science and Applied Research Conference on Oil and Gas Geological Exploration and Development, GEOMODEL 20142014.

[10] Anikin IV, Zinoviev IP. Fuzzy control based on new type of Takagi-Sugeno fuzzy inference system. In2015 International Siberian Conference on Control and Communications (SIBCON) 2015 May 21 (pp. 1-4). IEEE.

[11] Anikin I, Zinoviev I. New type of takagi-sugeno fuzzy inference system as universal approximator. Applied Mechanics and Materials. 2014 Aug 8;598:453-8.

[12] Gluhih IN, Piankov VN, Zabolotnov AR. Situational models in corporative knowledge base on geologicaltechnical measures know-how. NEFTYANOE KHOZYAISTVO. 2002 Jun 1(6):45-8.

[13] Alekseev A, Katasev A, Kirillov A, Khassianov A, Zuev D. Prototype of Classifier for the Decision Support System of Legal Documents. CEUR Workshop Proceedings. 2020; 2543:328-335.

[14] Alekseev AA, Zuev DS, Katasev AS, Tutubalina EV, Khassianov AF. Intellectual information decision support system in the field of economic justice. Nauchnyy servis v seti Internet: trudy XIX Vserossiyskoy nauchnoy konferentsii (17-22 sentyabrya 2018 g., g. Novorossiysk), Moscow, Keldysh Institute of Applied Mathematics. 2018.

[15] Baghapour MA, Shooshtarian MR, Zarghami M. Process Mining Approach of a New Water Quality Index for LongTerm Assessment under Uncertainty Using ConsensusBased Fuzzy Decision Support System. Water Resources Management. 2020 Feb;34(3):1155-72.

[16] Katasev AS, Kataseva DV. Expert diagnostic system of water pipes gusts in reservoir pressure maintenance processes. In2016 2nd International Conference on Industrial Engineering, Applications and Manufacturing (ICIEAM) 2016 May 19 (pp. 1-5). IEEE.

[17] Muslimov R, Plotnikova I. Modeling the development of oil fields, considering the mature fields reforming and refill by the deep hydrocarbons. Neftyanoe Khozyaystvo - Oil Industry. 2019;3:56-60.

[18] Muslimov RK, Plotnikova IN. Consideration of the processes of oil deposit reformation during long-term operation and deep feeding in modeling the development of oil fields. Георесурсы. 2018;20(3 (eng)):186-192.

[19] Altunin AE, Gordeev AO, Zemtsov YV, Zimin PV, Semukhin MV. Development of an automated matching algorithms geological and technical measures and criteria Well-ranking candidates on the basis of fuzzy sets (Russian). Oil Industry Journal. 2016 Sep 1;2016(09):94-9.

[20] Caumon G. Geological objects and physical parameter fields in the subsurface: a review. InHandbook of Mathematical Geosciences 2018 (pp. 567-588). Springer, Cham.

[21] Kobrunov AI, Kuleshov VE, Mogutov AS, Dorogobed AN. Prediction of hydrocarbon deposit physical and geological commercial parameters under conditions of data uncertainty. Neftyanoe khozyaystvo - Oil Industry. 2014;7: 78-80.

[22] Perfilieva IG, Yarushkina NG, Afanasieva TV, Romanov AA. Web-based system for enterprise performance analysis on the basis of time series data mining. InProceedings of the First International Scientific Conference "Intelligent Information Technologies for Industry”(IITI'16) 2016 (pp. 75-86). Springer, Cham.

[23] Katasev AS. Neuro-fuzzy model of fuzzy rules formation for objects state evaluation in conditions of uncertainty. Computer research and modeling. 2019;11(3):477-92.

[24] Ha SH. Applying knowledge engineering techniques to customer analysis in the service industry. Advanced Engineering Informatics. 2007 Jul 1;21(3):293-301.

[25] Neaga EI. Semantics enhancing knowledge discovery and ontology engineering using mining techniques: A crossover review. InKnowledge Discovery and Data Mining: Challenges and Realities 2007 (pp. 163-188). IGI Global. 
[26] Uddagiri C, Khare N. Introduction to Concept Modifiers in Fuzzy Soft Sets for Efficient Query Processing. InEmerging Research in Data Engineering Systems and Computer Communications 2020 (pp. 669-676). Springer, Singapore.

[27] Bouchon-Meunier B, Marsala C. Fuzzy modifiers at the core of interpretable fuzzy systems. InFifty Years of Fuzzy Logic and its Applications 2015 (pp. 51-63). Springer, Cham.

[28] Chen CL, Chen SC, Kuo YH. The reduction of interval type-2 LR fuzzy sets. IEEE Transactions on Fuzzy Systems. 2013 Aug 8;22(4):840-58.

[29] Amirah AF, Isa Z. Generating project risk membership functions based on experts' estimates and alpha-cut variations. InJournal of Physics: Conference Series 2020 Mar 1 (Vol. 1489, No. 1, p. 012018). IOP Publishing.
[30] Dagaeva M, Garaeva A, Anikin I, Makhmutova A, Minnikhanov R. Big spatio-temporal data mining for emergency management information systems. IET Intelligent Transport Systems. 2019 Sep 5;13(11):1649-57.

[31] Chupin MM, Katasev AS, Akhmetvaleev AM, Kataseva DV. Neuro-Fuzzy Model in Supply Chain Management for Objects State Assessing. Int. J Sup. Chain. Mgt Vol. 2019 Oct;8(5):201-208.

[32] Shushura O, Asieieva L, Husyeva I, Stepanov M, Datsiuk O. Construction of membership functions in fuzzy modeling tasks using the analytic hierarchy process. International Journal of Advanced Trends in Computer Science and Engineering. 2020; 9(3):. 2702-2707.

[33] Baron L, Achiche S, Balazinski M. Fuzzy decision support system knowledge base generation using a genetic algorithm. International Journal of Approximate Reasoning. 2001;28(2-3):125-148.

Panishchev Oleg Yurievich - Researcher of the Research Laboratory of Near Space Research, Kazan (Volga Region) Federal University. Graduated from Yelabuga State Pedagogical University with the degree in Physics, Informatics and Computer Science in 2003. Research interests: time series analysis, methods of analysis of non-equilibrium distributed systems.

Davydov Yuri Vladimirovich - Research Laboratory Assistant for Microwave Design and Radio Telecommunications, Kazan (Volga Region) Federal University. Graduated from Kazan (Volga Region) Federal University with the degree in Radiophysics in 2018. Research interests: methods of physical process mathematical modeling, automation of scientific experiments.

Anikin Igor Vyacheslavovich - Doctor of Engineering, Professor, Head of the Department of Information Security Systems at the Institute of Computer Technologies and Information Security, Kazan National Research Technical University named after A.N. Tupolev-KAI (KNITU-KAI). Graduated from Yelabuga State Pedagogical Institute with the degree in Mathematics, Informatics and Computer Science in 1997. He defended his doctoral dissertation in 2018. Research interests: information security, intelligent systems, neural networks, fuzzy systems.

Kataseva Dina Vladimirovna - postgraduate student, Senior Lecturer at the Department of Information Security Systems, the Institute of Computer Technologies and Information Security, Kazan National Research Technical University named after A.N. Tupolev-KAI (KNITU-KAI). Graduated from Kazan State Finance and Economics Institute with the degree in Accounting, Analysis and Audit in 2008, as well as with the master's degree in Informatics and Computer Engineering at KNRTU-KAI (2018). Research interests: intellectual analysis of time series, fuzzy logic, neural networks, decision support systems.

Katasev Aleksey Sergeevich - Doctor of Engineering, Professor of the Department of Information Security Systems at the Institute of Computer Technologies and Information Protection, Kazan National Research Technical University named after A.N. Tupolev - KAI (KNITU-KAI). He graduated from the Yelabuga State Pedagogical Institute with the degree in Physics, Informatics and Computer Engineering in 2002, as well as with the master's degree at KNITU-KAI in the field of Informatics and Computer Engineering in 2018. He defended his doctoral dissertation at KNRTU-KAI in 2019. His scientific interests: data mining technologies, formation of knowledge bases of expert systems, neural network, fuzzy and neuro-fuzzy modeling.

Akhmetvaleev Amir Muratovich - PhD in Engineering, Associate Professor of the Department of Information Security Systems at the Institute of Computer Technologies and Information Security, Kazan National Research Technical University named after A.N. Tupolev-KAI (KNITU-KAI). He graduated from Kazan State Technical University named after A.N. Tupolev in the field of "Information security of telecommunication systems" in 2008, as well as the master's degree at KNRTU-KAI in the field of "Informatics and computer technology" in 2012. He defended his PhD thesis at KNITU-KAI in 2018. Research interests: data mining, neural network modeling, assessment of human functional states by pupillary responses to illumination changes. 